\title{
Research parks feel the economic pinch
}

\section{Once lauded as incubators of high-tech jobs, science parks find themselves struggling in the new financial environment.}

Science parks, which have proliferated in recent years, face an uncertain future as the recession affects government budgets, university endowments and private investments - all of which science parks often depend on.

"A lot of big projects that were in the works are definitely feeling the crunch," says Anthony Townsend, a New Yorkbased research director at the Institute for the Future think tank. "Everything is being delayed or slowed down right now." Further delays may be in the offing; because science parks are longterm investments, the effects of an economic slowdown may not yet be fully evident.

In the United States, many research parks are supported by state and local governments, meaning that withering state budgets can have an immediate effect. "When legislators are choosing between cutting off funding for health care for low-income children as opposed to cutting funding for science parks,

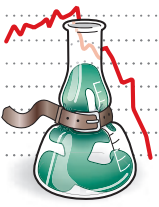

RECESSION WATCH in most cases the children are going to win - and they probably should," says Ross DeVol, director of regional economics at the Milken Institute in Santa Monica, California.

For instance, construction has slowed on the North Carolina Research Campus in Kannapolis as park planners anxiously await a decision on state funding. The state has a projected US $\$ 4$.6-billion budget shortfall for fiscal year 2010, which is likely to lead to budget cuts. Hoping that the securities markets will calm down, the city government of Kannapolis has also been waiting for more than a year to issue bonds to help fund the park.

That dependence on local governments underscores how important subsidies from universities and private companies can be for science parks. "We all need some type of subsidy - you can't just charge start-up companies the going rate," says Kevin O'Sullivan, president and chief executive of Massachusetts

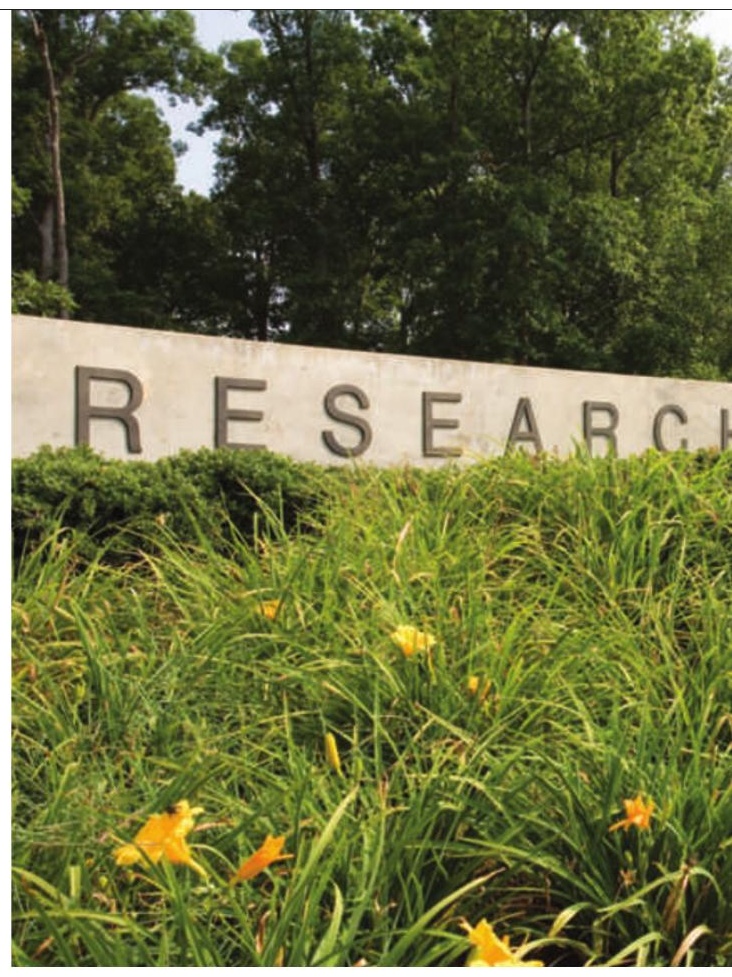

Biomedical Initiatives in Worcester, which runs three 'incubators' that foster growth in early-stage companies. Worcester Polytechnic Institute subsidizes the rent on one of O'Sullivan's buildings, and the state government has provided funds that the company uses to purchase shared equipment for its

\section{Astronomers lose access to military data}

The US military has abruptly ended an informal arrangement that allowed scientists access to data on incoming meteors from classified surveillance satellites.

The change is a blow to the astronomers and planetary scientists who used the information to track space rocks, especially those that burn up over the oceans or in other remote locations. "These systems are extremely useful," says Peter Brown, an astronomer at the University of Western Ontario in London, Canada. "I think the scientific community benefited enormously."

When the policy changed is unclear. The website Space.com reported the end of the relationship on 10 June, but Brown says that he was told at the beginning of this year that there would be no further data releases. Mark Boslough, a physicist at Sandia National Laboratories in Albuquerque, New Mexico, says he was told this spring that he could no longer publicly discuss the classified data to which he had some access. Neither scientist could give a reason for the end of the arrangement, and the United States Air Force, which operates the satellites, did not respond in time for Nature's deadline. The Air Force did issue a 16 March memo on the military classification of fireball data, but Nature could not confirm its contents.

The Defense Support Program satellite network is part of the Pentagon's early-warning system. Since 1970, 23 infrared satellites in the series have been launched into geosynchronous orbit to monitor the globe for missile launches or atmospheric nuclear blasts.

But the same infrared sensors were perfect for spotting fireballs as they streaked across the atmosphere, according to Brian Weeden, a former Air Force captain who now works at the Secure World Foundation, a non-profit organization based in Superior, Colorado. The satellites could precisely detect the time, position, altitude and brightness of meteors as they entered Earth's atmosphere. Weeden, who left the Air Force in 2007, says that the military didn't consider that information particularly useful, or classified. "It was being dropped on the floor," he says.

Under an informal arrangement, at least some of the data seem to have been provided on an ad-hoc basis to scientists studying meteorites. Often it came in the form of an anonymous, tersely worded e-mail describing the coordinates, altitude and size of a fireball. Brown, who has collected the data since 1994, declined to specify who sent the reports.

Even the short descriptions of events were enormously helpful. In 2002, Brown and his colleagues used a larger data set from the satellites to quantify the number of objects striking Earth each year (P. Brown et al. Nature 420, 294-296; 2002). Last year, they were used to narrow the search for remnants of the asteroid 2008 TC $_{3}$ in the Sahara Desert in North Africa, and they were also crucial in recovering a meteorite fragment in $\mathbf{2 0 0 0}$ from Tagish Lake in northern Canada. "In both 


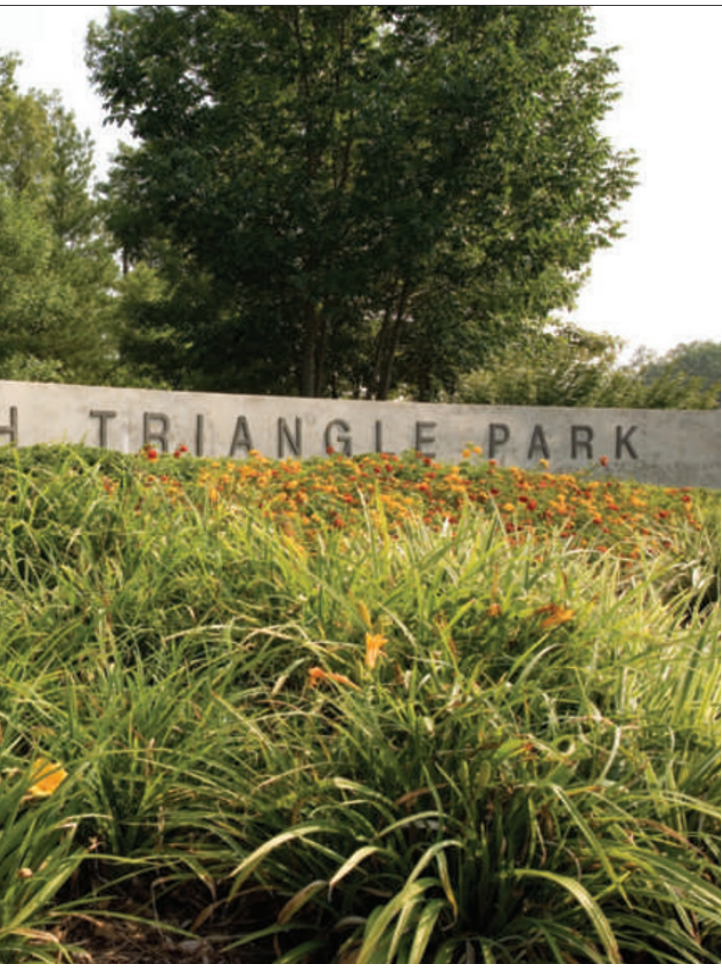

Even the flagship Research Triangle Park in North Carolina has experienced recent lay-offs.

laboratories. But now those state subsidies, currently $\$ 700,000$ a year, may be halved.

Some parks are still pushing ahead. The Bio-Research \& Development Growth Park

at the Donald Danforth Plant Science Center in St Louis, Missouri, opened on 16 June with more than $60 \%$ of its space already leased. Because lease negotiations for space in office parks can take a year, the St Louis space was probably filled before the economic meltdown began in earnest last autumn.

Some argue that slowing down projects can be a bad competitive decision. "It's a global marketplace now," says Gary Evans, US chief executive of Angle Technology, a consulting and venture-capital firm with US operations based in Charlottesville, Virginia. "Each project that gets delayed or shelved is just weakening the United States' competitive position overall.'

In Japan, the Kansai Science

"Are we going to have to consolidate one of our facilities next year?" City has not yet been significantly affected by the recession, says Seiji Hashimoto, planning manager of the Kansai Research Institute. He attributes this to the diversity of the park's tenants, which include research laboratories for pharmaceutical and electronics companies.

In Germany, the Innovation and Incubator Centre for Biotechnology in Martinsried has a waiting list for tenants, says Horst Domdey, managing director of $\mathrm{Bio}^{\mathrm{M}}$ Biotech Cluster Development in Martinsried, a consulting firm that advises the park. And last autumn, the French government renewed its $€ 1$.5-billion (US\$2.1-billion), three-year commitment to support the country's 71 'competitiveness clusters'.

Many are watching closely to see how science parks are faring in nations that are eager to enter the technology race. Singapore's Prime Minister Lee Hsien Loong has said that investment in its massive science-park projects, Biopolis and Fusionopolis, will continue apace despite the recession. Technology investment in the country has remained strong, as evidenced by the opening of pharmaceutical giant GlaxoSmithKline's new vaccine facility near Biopolis on 9 June. Meanwhile, Brazil, China and countries in the Middle East have continued to pour funds into burgeoning networks of science parks.

Some research parks and incubators are trying to help their tenants cope with the financial crunch. The United Kingdom's BioCity Nottingham has begun buying lab equipment and leasing it to resident laboratories. "What we don't want is a stagnating industry," says Glenn Crocker, BioCity chief executive.

For now, science parks will have to watch and wait. "We're going to get through this year, but next year are we going to have to consolidate one of our facilities? We just might," says O'Sullivan. "I'll cross that bridge when I get to it, but I'm acutely aware that this is coming."

Heidi Ledford

See Naturejobs, page 1022. of those cases it's hard to say whether this would have been picked up without the satellite data," Boslough says.

The data also provide a useful check against ground-based instruments monitoring lowfrequency sound waves and dust from the fireball explosions, says Brown.

Although the reason for ending the arrangement remains unclear, Weeden notes that it coincides with the launch of a new generation of surveillance satellites. The US\$10-billion-plus Space-Based Infrared System will provide a more detailed infrared picture of Earth for battlefield surveillance, earlywarning alerts and the US missile defence programme.

The first of these satellites was launched in 2006 in a highly elliptical orbit and entered operational service in November 2008, a month after Brown

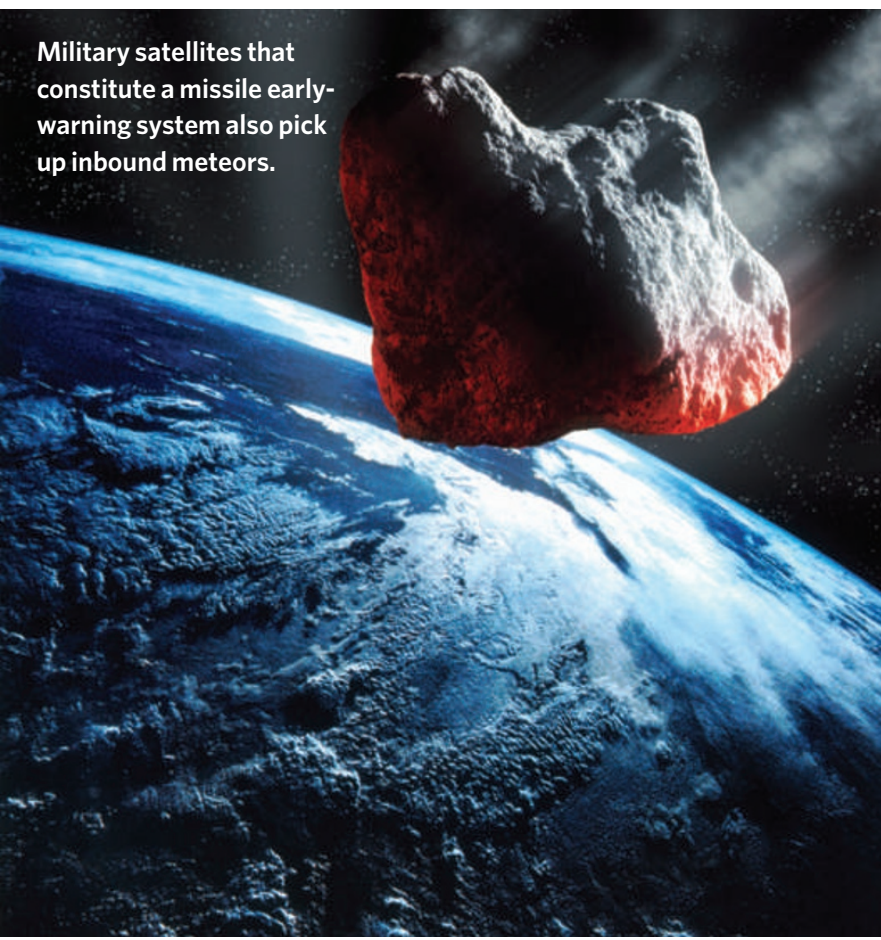

received his last report. In its final configuration, the system will include at least two satellites in highly elliptical orbit and three or more geosynchronous satellites for a whole-Earth view.

Weeden speculates that the Pentagon may not want details of the new satellites' capabilities to be made public, or it may simply lack the expensive software needed to handle classified and declassified data simultaneously. "The decision may have been made that it was perhaps too difficult to disclose just these data," he says.

Brown says that whatever the reason, the end of the relationship has left the tight-knit meteorite community smarting. The global reach of the satellites and the data they supplied were unparalleled, he says.

"There's nothing else that even comes close," he says.

Geoff Brumfiel 